Original Research Paper

\title{
Enzymatic Hydrolysis of Pretreated Kenaf using a Recombinant Xylanase: Effects of Reaction Conditions for Optimum Hemicellulose Hydrolysis
}

\author{
${ }^{1}$ Nur Izyan Wan Azelee, ${ }^{2}$ Jamaliah Md Jahim, \\ ${ }^{3}$ Ahmad Fauzi Ismail, ${ }^{4}$ Siti Fatimah Zaharah Mohamad Fuzi, \\ ${ }^{1}$ Roshanida A. Rahman, ${ }^{1}$ Nazlee Faisal Ghazali and ${ }^{1}$ Rosli Md Illias \\ ${ }^{I}$ Department of Bioprocess Engineering, Faculty of Chemical Engineering, \\ Universiti Teknologi Malaysia, 81310, Skudai, Johor Bahru, Johor Darul Takzim, Malaysia \\ ${ }^{2}$ Department of Chemical and Process Engineering, \\ Universiti Kebangsaan Malaysia, 43600 UKM Bangi, Selangor Darul Ehsan, Malaysia \\ ${ }^{3}$ Advanced Membrane Technology Research Centre, \\ Universiti Teknologi Malaysia, 81310, Skudai, Johor Bahru, Johor Darul Takzim, Malaysia \\ ${ }^{4}$ Department of Technology and Heritage, Faculty of Science, Technology and Human Development, \\ Universiti Tun Hussein Onn Malaysia, 86400, Parit Raja, Batu Pahat, Johor Darul Takzim, Malaysia
}

Article history

Received: 29-06-2015

Revised: 24-04-2016

Accepted: 26-04-2016

Corresponding Author: Rosli Md Illias

Department of Bioprocess

Engineering, Faculty of

Chemical Engineering,

Universiti Teknologi Malaysia,

81310, Skudai, Johor Bahru,

Johor Darul Takzim, Malaysia

Email: r-rosli@utm.my

\begin{abstract}
An efficient hemicellulose hydrolysis has now become a crucial step for xylooligosaccharides production for food additives and nutraceuticals industries. In this study, xylanase hydrolysis of pretreated hemicellulosic kenaf (Hibiscus cannabinus) for substantial hemicellulose hydrolysis was demonstrated. Experiments were performed primarily to investigate the effect of several critical reaction conditions towards the enzymatic hydrolysis of the pre-treated kenaf. The effects of various ranges of reaction conditions (substrate loading, xylanase loading, $\mathrm{pH}$, temperature and time) were systematically and thoroughly studied. The study of hemicellulosic kenaf conversion using single enzyme was proven to effectively yield up to $59 \%$ of conversion after $48 \mathrm{~h}$ incubation using $3 \%$ $(\mathrm{w} / \mathrm{v})$ of substrate loading and $400 \mathrm{U}$ of xylanase loading at $50^{\circ} \mathrm{C}$ in $\mathrm{pH} 4.0$ buffer systems. The use of a single xylanase on the pre-treated kenaf was a key parameter in understanding the action of the main hemicellulose degrading enzyme towards hydrolysing the hemicellulose backbone of the pre-treated kenaf. Enzyme feeding strategy was also conducted and the results revealed that a batch feeding strategy of $400 \mathrm{U}$ xylanase loading yielded the highest hemicellulose hydrolysis compared to the other fed batch enzyme feeding strategy. It was concluded that each reaction conditions and enzyme feeding strategy gave a significant impact towards the enzymatic hydrolysis and the use of optimum reaction conditions resulted in a high product yield at the end of the reaction. With the discovery of the importance of each reaction conditions involved in a hydrolysis, this study highlights the need for a comprehensive investigation on the reaction conditions using a mixture of enzymes towards achieving a complete hydrolysis with a higher product yield.
\end{abstract}

Keywords: Enzymatic Hydrolysis, Hemicellulose, Kenaf, Reaction Conditions, Xylanase

\section{Introduction}

Lignocellulosic biomass is the non-starch, fibrous part of a plant material which is useful for its renewability and abundance (Otieno and Ahring, 2012a). It is now considered the most promising feedstock for producing biofuels and other biochemical due to its versatility, availability and low 
cost (Gonçalves et al., 2012). Being non-edible portion of the plant, lignocellulosic biomass materials are drawing more attention as these resources are carbon neutral and hence do not cause additional increases in the carbon dioxide level in the earth's atmosphere (Öztürk et al., 2010). Lignocellulosic complex lattice biomolecule structures consist of three basic parts; cellulose (35-50\%), hemicellulose (20$35 \%)$ and lignin (5-30\%), along with smaller amounts of pectin, protein, extractives and ash. Nevertheless, the composition of each constituent varies from one plant species to another (Lin et al., 2010). The cellulose and hemicellulose are both polymers built up by long chains of sugar units, which (after pretreatment and hydrolysis) can be converted into intermediate products. The majority of the previous studies on hydrolysis of lignocellulosic biomass have focused on the cellulose (Ninomiya et al., 2012; Tippkötter et al., 2014; Ying et al., 2014). Only a few of them performed their study on the hemicellulose (Qiu et al., 2012) and hence, this will be the main focus of this study.

Hemicellulose, the second most abundant polysaccharide in the world (Peng et al., 2012a), acts as a potential substance as a reserve for fuel and support of cellulose. This fraction presents branched structure composed of pentoses (D-xylose and Larabinose), hexoses (D-galactose, D-mannose and Dglucose) and small amounts of acetic and uronic acids (D-glucuronic, D-4-O-methyl-glucuronic and Dgalacturonic) (Canilha et al., 2013). Since the main component of the hemicellulosic fraction is xylan, this heteropolymers has been converted into many different value-added products such as xylose, xylitol, antioxidants and xylooligosaccharides (Akpinar et al., 2009). However, a good pre-treatment method needs to be applied prior to hydrolysis to remove as much lignin as possible and to enable an efficient hydrolysis. The lignin layer acts as a big barrier which may result in a poor substrate degradation. In this context, a previously well pre-treated substrate with the highest lignin removal was used (Wan Azelee et al., 2014).

The enzymatic route has been receiving a great deal of attention as an alternative technology for hydrolysis of lignocellulosic biomass due to mild operation condition and minimal formation of degrading compounds (Silva et al., 2015). Enzymatic methods are desirable as they do not requires any special equipment to be operated at high temperatures (Wang and Lu, 2013), are able to perform reactions with lower energy consumption and lower environmental impact (Mussatto et al., 2008). However, the enzymatic digestion of hemicellulose fractions in natural biomass substrates are always limited by its complex structure and components (Lin et al., 2010). Hence, the optimization of critical reaction parameters including substrate concentrations (Hardt et al., 2014), enzyme loadings (Carlos et al., 2012), pH (Romsaiyud et al., 2009), temperature (Jin et al., 2011) and hydrolysis time (Akpinar et al., 2009; Ovissipour et al., 2009) should be performed in relation to different substrates.

There is a lot of lignocellulosic biomass available all around the world. Among alternative biomass resources, kenaf (Hibiscus cannabinus) is a good candidate for bioenergy because of its fast growth rate and abundant biomass production (Öztürk et al., 2010). Kenaf also possess several features which are responsible to be considered as an ultimate choice for biomass and bioenergy production. Kenaf has low feedstock, high biomass content and negligible pesticide requirement along with low crop rotation (Saba et al., 2015). Currently, many countries have paid more attention to kenaf research and promotion because of its high biological efficiency and wide ecological adaptability (Saba et al., 2015). Kenaf is a natural complex lignocellulosic biomass composed of intertwined cellulose, hemicellulose and lignin components. In the hydrolysis of hemicellulosic kenaf backbone (xylan), xylanase must firstly penetrate cellulose and lignin barriers in order to bind and digest the xylan (Wang and Lu, 2013).

In this study, the suitability of the pre-treated kenaf from the previous alkaline-acid pre-treatment method (Wan Azelee et al., 2014) was tested with enzymatic xylanase hydrolysis under five different reaction conditions. The effectiveness of xylanase hydrolysis on pre-treated kenaf was also compared with the untreated kenaf with respect to the percentage of hemicellulose hydrolysis. The aim of this work is to determine the effect of several important reaction conditions that may significantly influence the enzymatic hydrolysis. To the best of our knowledge, this is the first study investigating the effect of several reaction conditions on hemicellulosic kenaf hydrolysis using a single xylanase enzyme that managed to produce a substantial level of hemicellulose hydrolysis.

\section{Materials and Methods}

\section{Chemicals and Raw Material}

Beechwood xylan and all other chemicals used in this study were of analytical grade obtained either from Sigma-Aldrich (St. Louis, MO, USA), or Merck Chemical Companies (Deisenhofen, Germany) unless specified. Kenaf was obtained from the Everise Crimson Sdn. Bhd., a kenaf processing company in Bachok, Kelantan (North-East Malaysia).

\section{Lignocellulosic Biomass Preparation}

Raw kenaf stem was oven dried until constant weight and ground using a mechanical grinder (Model RT-20, China) to obtain particle sizes of 40-60 mesh. Dried 
kenaf stem was then pre-treated with $7 \% \mathrm{Ca}(\mathrm{OH})_{2}$ for $1.5 \mathrm{~h}$ followed by $20 \%$ peracetic acid (PPA) for subsequent $2 \mathrm{~h}$ (Wan Azelee et al., 2014). The biomass was filtered and thoroughly washed with distilled water several times until neutral $\mathrm{pH}$ before oven-dried to a constant weight. The biomass was stored in airtight containers at room temperature before use. These two kenaf samples, untreated and treated, were tested for compositional analysis. Moisture, ash, cellulose, hemicellulose and lignin were determined according to the method provided by American Society for Testing and Materials (ASTM).

\section{Cloning and Expression of Recombinant Xylanase} in Pichia Pastoris X33

Prior to cloning of endo- $\beta-1,4$-xylanase gene (Xyn2), Reverse Transcription Polymerase Chain Reaction (RTPCR) amplifications were carried out using primers designed from an mRNA sequence of Trichoderma reesei strain QM6a (NCBI accession number: U24191). Oligonucleotide primers were designed as follow: XynF 5'AATGTCGACCAGACGATTCAGCCCGGCACGGG CTACAAC-3' and XynR 5'AATGCGGCCGCTTTAGCTTAGCTGACGGTGATG GAAGCAGA-3' supplemented with SalI and NotI restriction sites, respectively. The gene was cloned into vector pPICZ $\alpha \mathrm{A}(3,600 \mathrm{bp})$ located downstream of the Pichia pastoris 5'and 3' -terminus, respectively. The plasmid harboring pPICZ $\alpha-X y n 2$ was transformed into $E$. coli DH5 $\alpha$ (GIBCOBRL, Grand Island, NY, USA) and selected under the pressure of $25 \mathrm{~g} \mathrm{~mL}^{-1}$ Zeocin (Invitrogen). The plasmid was purified and linearized by $X$ hoI for transformation into the expression host $P$. pastoris X33 (EasySelect Pichia Expression Kit, Invitrogen, Carlsbad, CA, USA). One transformant, X3371-61 was found to feature the most pronounced xylanase activity and was used as the xylanaseproducing strain for this study.

The recombinant grew and expressed heterologously in BMGY $[1 \%$ yeast extract, $2 \%$ peptone, $100 \mathrm{mM}$ potassium phosphatate (pH 6.0), 1.34\% YNB, 0.0004\% biotin and $1 \%$ glycerol] and BMMY $[1 \%$ yeast extract, $2 \%$ peptone, $100 \mathrm{mM}$ potassium phosphatate $(\mathrm{pH} 6.0)$, $1.34 \%$ YNB, $0.0004 \%$ biotin and $0.5 \%$ methanol] medium with $P$. pastoris as the selected host (He et al., 2009). The enzyme was partially purified using an ultrafiltration unit (TFF minimate cassette, Pall brand) of $10 \mathrm{kDa}$.

\section{Enzyme Assay}

Endo-1,4- $\beta$-xylanase activity assay was carried out by mixing $100 \mu \mathrm{L}$ of enzyme solution with $450 \mu \mathrm{L}$ of $2 \%$ Beechwood xylan (Sigma) solution in $200 \mu \mathrm{L}$ sodium acetate buffer ( $\mathrm{pH} 5.0)$ at $50^{\circ} \mathrm{C}$. Samples were taken out after $5 \mathrm{~min}$ of incubation and the reaction was immediately stopped by boiling the samples for $15 \mathrm{~min}$ after the addition of $750 \mu \mathrm{L}$ DNS solution and $50 \mu \mathrm{L}$ $\mathrm{NaOH}$. DNS method was used for the determination of reducing sugar concentration released during the enzymatic reaction. One unit is defined as the quantity of enzymes that liberates $1 \mu \mathrm{mol}$ of xylose per min at $50^{\circ} \mathrm{C}$, pH 5.0 (Bailey et al., 1992). The assay were performed in triplicates and were corrected for blank and controls.

\section{Reducing Sugar Measurement}

Total reducing sugars were quantified according to the dinitrosalicylic acid (DNS) method using a modified DNS reagent (Miller, 1959). A standard curve for the DNS assay was prepared using xylose as a suitable standard and expressing the activity in terms of reducing sugars released as D-xylose equivalents. The assay was performed in triplicates.

\section{Enzymatic Hydrolysis of Hemicellulose}

Different ranges of parameters (substrate loading, enzyme loading, $\mathrm{pH}$, temperature and time) were tested for hydrolysing the pre-treated kenaf. Enzymatic hydrolysis of biomass was carried out with a total of 20 $\mathrm{mL}$ reaction volume. The range of each parameter screened is tabulated in Table 1 . The best chosen value of the initial parameter was used for subsequent parameter screening. All hydrolysis was standardized using $50 \mathrm{mM}$ sodium acetate buffer with $0.02 \%$ tetracycline $\mathrm{HCl}$ to prevent microbial contamination. All the hydrolysis was incubated in an orbital shaker (Sastec model) agitated at constant $200 \mathrm{rpm}$. Liquid samples were withdrawn from the reaction media periodically, centrifuged and filtered. The hydrolysis were stopped by drawing $750 \mu \mathrm{L}$ samples from the hydrolysate suspension, added with $750 \mu \mathrm{L}$ DNS solution and $50 \mu \mathrm{L}$ of $1 \mathrm{M} \mathrm{NaOH}$ prior boiling for $15 \mathrm{~min}$. The samples were cooled to room temperature, centrifuged at $13,000 \times \mathrm{g}$ for $5 \mathrm{~min}$ and the supernatants were used to monitor reducing sugar yields. The efficiency of the hydrolysis reactions for the optimization of the hydrolysis conditions was based on quantification of reducing sugars. All parameter screenings were carried out in triplicates and the standard deviations were shown in error bars. The hemicellulose (xylan) hydrolysis of the pre-treated kenaf were eventually calculated as in Equation 1 (Sharma et al., 2004):

$$
\begin{aligned}
& \text { Xylan hydrolysis }(\%) \\
& =\frac{\text { The amount of sugar produced } \times 0.88}{\text { The amount of hemicellulosic xylan in pretreated kenaf }} \\
& \times 100 \%
\end{aligned}
$$

where, 0.88 is the correction factor to compensate for the addition of a water molecule during hydrolysis. 
Table 1. Range of five parameters screened

\begin{tabular}{ll}
\hline Parameter & Range of values \\
\hline Sub. conc. ${ }^{\mathrm{a}}(\mathrm{w} / \mathrm{v}) \%$ & $0.5,1,2,3,4,5$ \\
Enzyme loading, U & $50,100,200,300,400,500,600,700$ \\
$\mathrm{pH}$ & $3.6,4.0,4.4,4.8,5.0,5.6$ \\
Temperature, ${ }^{\circ} \mathrm{C}$ & $30,40,50,55,60$ \\
Time, $\mathrm{h}$ & $6,12,24,48,732,96,120$ \\
\hline
\end{tabular}

${ }^{\mathrm{a}}$ Sub. Conc. $=$ Substrate concentration

\section{Results and Discussion}

\section{Kenaf Stem Composition}

Raw kenaf has the following compositions (\% dry weight): Cellulose, 37.29; hemicellulose, 51.83 and lignin, 14.38 (Wan Azelee et al., 2014). The high content of hemicellulose in kenaf gives an advantage for the production of high xylose and xylooligosaccharides. However, these chemical compositions may vary for different lignocelluloses depending on the genetics, growth environment and age of the plant, the harvest method of the biomass as well as the storage conditions of the raw material (Hames et al., 2003; Wan Azelee et al., 2014). In order to make the carbohydrates in the lignocellulose accessible for enzymatic hydrolysis, a pretreatment step is necessary (Valtcheva et al., 2003). Two different pre-treatment conditions, $\mathrm{Ca}(\mathrm{OH})_{2}-\mathrm{PPA}$ were performed and most of the lignin compositions were successfully removed while maintaining high hemicellulose composition. The combinations of PPA together with the $\mathrm{Ca}(\mathrm{OH})_{2}$ have successfully enhanced the removal of the lignin composition from the kenaf compared to the pre-treatment with $\mathrm{Ca}(\mathrm{OH})_{2}$ alone (Wan Azelee et al., 2014). This is because, PPA is known as a lignin-oxidation pre-treatment with low-energy input. The use of PPA treatment has also improved enzymatic digestibility of hybrid poplar and sugar cane bagasse with no need of high temperatures (Teixeira $e t$ al., 1999; Zhao et al., 2008). Moreover, the $\mathrm{Ca}(\mathrm{OH})_{2}$ treatment are helpful in reducing the peracetic acid requirements in the pre-treatment (Teixeira et al., 1999). The chemical compositions for the unpre-treated and pretreated kenaf are summarized in Table 2.

Hydrolysis using suitable enzymes can effectively liberate simple sugars from hemicellulosic materials due to their substrate specificities. In the current study, endoxylanase was used with the aim to hydrolyze the main xylan backbone of kenaf hemicellulose for the liberation of high reducing sugar yield. However, the enzymatic hydrolysis can be influenced as well as hampered by various reaction conditions such as substrate loading, enzyme loading, $\mathrm{pH}$, temperature and time. Therefore, these reaction conditions were screened and analyzed in the present study.
Table 2. Chemical compositions in raw and pre-treated kenaf ${ }^{\mathrm{a}, \mathrm{b}}$

\begin{tabular}{lll}
\hline Chemical composition & Raw kenaf & Pre-treated kenaf \\
\hline Cellulose & $37.29 \pm 0.02$ & $35.86 \pm 0.03$ \\
Hemicellulose & $51.83 \pm 0.04$ & $45.46 \pm 0.03$ \\
Lignin & $14.38 \pm 0.01$ & $5.89 \pm 0.01$ \\
\hline
\end{tabular}

${ }^{a}$ Results are shown in \% w/w basis with \pm SD. SD is the standard deviation based on the average of three replicates

${ }^{\mathrm{b}}$ Moisture-free basis

\section{The Effect of Substrate Concentrations on Hemicellulosic Kenaf Hydrolysis}

Enzymatic kenaf hydrolysis at high solid concentrations is advantageous from an environmental point of view. However, increased substrate concentrations (for insoluble substrate) up to a certain concentration have unfavourably resulted in a concentration effect or solids effect with a decreased in hydrolysis rate at constant enzyme-to-substrate ratios and a decreased maximum attainable degree of hydrolysis (DH \%) (Hardt et al., 2014). In this study, different substrate concentrations of kenaf were screened from 0.5 to $5 \% \quad(\mathrm{w} / \mathrm{v})$. Figure 1 indicates that hemicellulosic kenaf hydrolysis gradually increased up to 3.3 -fold from 0.5 to $3 \%$ substrate concentrations. Generally, for most cases, the efficiency of an enzymatic hydrolysis increases with the increase in substrate concentration. Subsequently, it could be clearly understood that the higher amount of substrates in the reaction medium indicates to larger surface areas that are available for the enzyme active sites to attack.

The profile for a biological reaction, however, is not always in proportional with each other. Further enhancements in the substrate concentration of kenaf $(>3 \% \mathrm{w} / \mathrm{v})$ resulted in a decrease of hemicellulose hydrolysis (Fig. 1). The distinct decrease from 16.5 to $15.4 \%$ in hemicellulose hydrolysis at 4 and $5 \%(\mathrm{w} / \mathrm{v})$ of substrate concentration, respectively could be strongly related to the reduction of water content in the reaction medium which eventually caused mass transfer limitations. This phenomenon was clearly explained by Hardt et al. (2014), where a higher solid concentration resulted in a higher viscosity and therefore higher diffusion time, especially for substrates that cannot be dissolved completely (insoluble) in water. Thus, the smoothness of the enzyme, substrate and product diffusion was hindered, leading to a non-homogeneous distribution of enzyme and substrate (Roberts et al., 2011). Uçkun Kiran et al. (2013) have previously explained that increase solute and solid content in the medium can cause mass transfer limitations which could decrease the xylanase activity, thus further increases the enzyme inactivation. The ability of the enzyme to diffuse is impaired above a critical substrate concentration depending on a variety of aspects (type and the chemical composition of substrate used, reaction conditions etc.) (Cheng and Prud'homme, 2000; Modenbach and Nokes, 
2013). Increasing solid concentrations can also favour enzyme inhibitions since they can hamper the diffusion of the product away from the reactive site (Hodge et al., 2009). This may also be one of the main factors of the decreased in hemicellulose hydrolysis of kenaf at 4 and $5 \%(\mathrm{w} / \mathrm{v})$ of substrate loading (Fig. 1).

Furthermore, it is pervasively known that many microbiological and enzymatic processes slow down substantially at low water activity. In the present study, as the substrate concentration was increased greater than $3 \%(\mathrm{w} / \mathrm{v})$, the water activity decreased to a non-optimal condition for hemicellulosic kenaf hydrolysis. The amount of water, as well as the ratio between substrate and water, play a central role in enzymatic hydrolysis since water is important as a reactant in the hydrolysis reaction (Hardt et al., 2014). This theory was supported by the different enzyme: Substrate ratio (c1 and c2) performed in this study as shown in Fig. 2.

The results of the current study highlighted that the optimal ratio between solid and liquid was $3 \mathrm{~g}$ kenaf in 100 $\mathrm{mL}$ buffer for particle size mixtures which ranged from 1 to $5 \mathrm{~mm}$. Increasing the substrate concentrations above the optimum level of solid and liquid ratio resulted in ineffective mixing of the enzyme mixture with the substrate (Cara et al., 2007; Modenbach and Nokes, 2013).

\section{The Effect of Enzyme Loadings on Hemicellulosic Kenaf Hydrolysis}

Based on Fig. 2, the efficiency of enzymatic hydrolysis of hemicellulosic xylan was also depended on enzyme loading, as shown by the amount of reducing sugar released during the reaction. The enzyme loading can vary over a wide range of unit activities depending on the type and concentration of substrates and the protocol used (Carlos et al., 2012). It was evident that the reducing sugar yield of hemicellulose was effectively enhanced by the addition of higher xylanase loadings. The optimum substrate loading previously obtained (3\% $\mathrm{w} / \mathrm{v})$ was used for further enzyme loading study (50-700 $\mathrm{U})$. The enzymatic reactions were performed at a constant temperature of $50^{\circ} \mathrm{C}$ in $\mathrm{pH} 5.0$ buffer system for $24 \mathrm{~h}$. It was found that the hydrolysis efficiency of kenaf increased sharply at the initial enzyme loading range $(50-400 \mathrm{U})$. Up to $31 \%$ hemicellulose hydrolysis of kenaf was achieved at $400 \mathrm{U}$ of xylanase loading. This was a great achievement as increase of the enzyme loadings can greatly influence a better hydrolysis compared to the lower enzyme loadings performed on brewer's spent grain (Mussatto et al., 2008). Sun and Chen (2002) have reported that cellulase loadings can also vary from 7 to $33 \mathrm{FPU} / \mathrm{g}$ cellulose, depending on the type and concentration of substrates. Nevertheless, the use of higher enzyme loading $\left(>30 \mathrm{IU} \mathrm{mL}^{-1}\right)$ in the hydrolysis of wheat bran xylan resulted in the decrease of xylooligosaccharides (XOS) yield (Samanta et al., 2012).

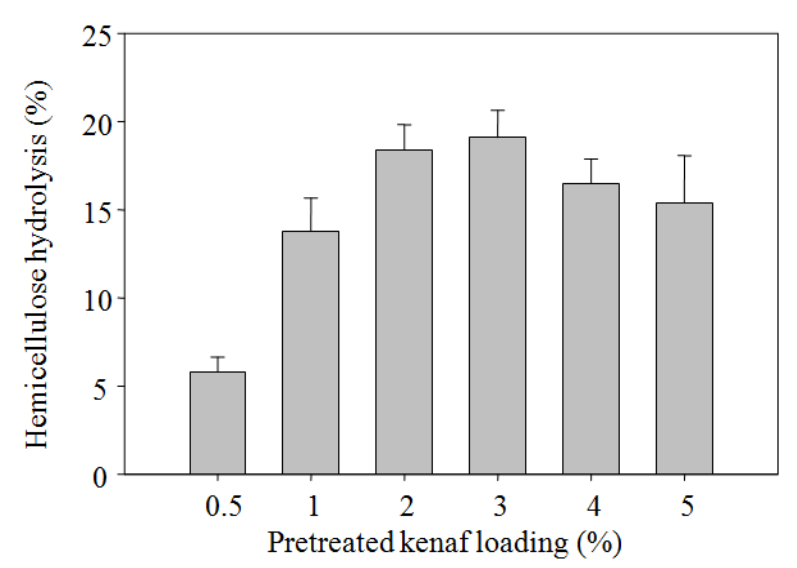

Fig. 1. Effect of different substrate loadings on hemicellulose hydrolysis of pre-treated kenaf. The hydrolysis was carried out using $100 \mathrm{U}$ of $\mathrm{Xyn} 2$ at $50^{\circ} \mathrm{C}$ in acetate buffer of $\mathrm{pH} 5.0$ for $24 \mathrm{~h}$. Vertical bars represent standard deviations based on the average

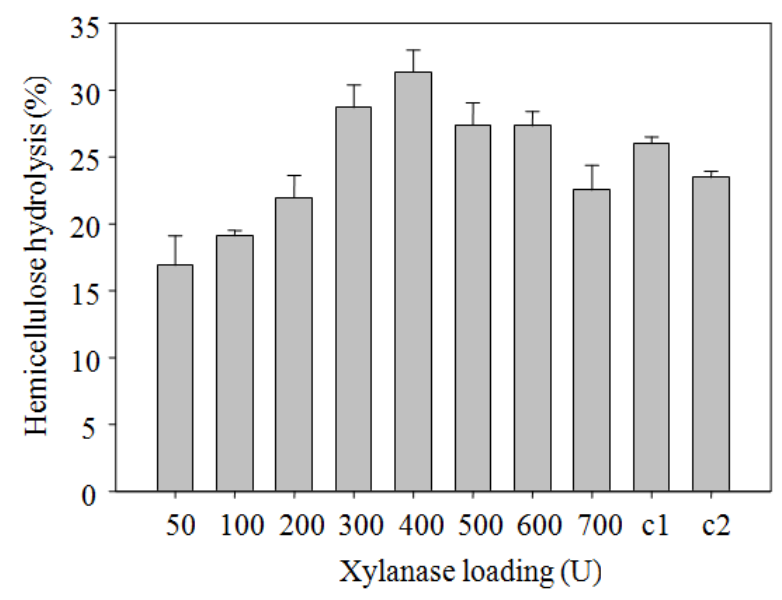

Fig. 2. Effect of different enzyme loadings (Xyn2) on hemicellulose hydrolysis of pre-treated kenaf. The hydrolysis was carried out using $3 \%$ of pre-treated kenaf at $50^{\circ} \mathrm{C}$ in acetate buffer of $\mathrm{pH} 5.0$ for $24 \mathrm{~h} . \mathrm{c} 1$ and $\mathrm{c} 2$ are negative controls performed under the same reaction conditions but with different enzyme: Substrate ratio (c1 $=300 \mathrm{U}: 2.25 \%, \mathrm{c} 2=500 \mathrm{U}: 3.75 \%$ ). Vertical bars represent standard deviations based on the average of at least three replicates and $p$-value is $0.0424(\mathrm{p}<0.05)$

This may be due to the low hemicellulose composition existed in the substrate (only 28.1\%) where with higher enzyme loading have negatively affected the hydrolysis yield.

In the contrary, a higher enzyme loading was needed $(>50 \mathrm{U})$ in order to achieve a significant hemicellulose hydrolysis $(>15 \%)$ from kenaf (with $45.46 \%$ of hemicellulose composition) (Fig. 2). The high hemicellulose composition available in the pre-treated kenaf had provided with a large surface area for the high enzyme 
loading to hydrolyze the substrate. Moreover, many other substrates exhibited lower hemicellulose composition $(<$ 28\%) (Mussatto et al., 2008; Pallapolu et al., 2011; Samanta et al., 2012) compared to the kenaf and thus requires lower enzyme loadings. Nevertheless, the hydrolysis efficiency gradually and unexpectedly reduced when the enzyme concentration exceeded a certain level $(>400 \mathrm{U})$. This phenomenon could be explained in three aspects: (1) The surface area of hemicellulose was not sufficient. It was assumed that the initially adsorbed enzyme on the fiber surface formed only a single layer in such a way that the excess of enzyme molecules were adsorbed, consequently forming additional multiple layers. Hence, only the enzyme adsorbed in the first layer participated in the hydrolysis. This superficially adsorbed enzyme on the first layer of the fiber would play a significant role in the hydrolysis, but would also restrict the diffusion process of enzyme through the structure of the substrate (Carrillo et al., 2005) and most likely impact the effectiveness of further loaded enzymes; (2) the surface area of enzyme was composed of active and inactive fractions with only those of biomass molecules adsorbed on the active fraction that participated in the hydrolysis (Lin et al., 2010); and (3) high enzyme loadings could overcrowd accessible hemicellulose chains and it was believed that this reduction in percentage of hemicellulose hydrolysis was due to the lack of available binding sites on the hemicellulose, thus reducing the rate at which hemicellulose was hydrolyzed (Modenbach and Nokes, 2013). All these possibilities eventually led to less catalysis and thus lower hemicellulose hydrolysis of kenaf at higher enzyme loading.

\section{The Effect of $p H$ on Hemicellulosic Kenaf Hydrolysis}

The effect of $\mathrm{pH}$ on the hemicellulose hydrolysis was also studied. It has been proven that $\mathrm{pH}$ significantly affects the total net charge of enzymes (Romsaiyud et al., 2009). During biotic hydrolysis, the lignocelluloses are hydrolyzed by extracellular hydrolytic enzymes excreted by hydrolytic microorganisms which prefer sub-acid to neutral conditions (Chen et al., 2012). Hence, in this study, the effect of different $\mathrm{pH}$ values, ranging from 3.6 to 5.6, was analyzed on alkali-acid pre-treated kenaf (Fig. 3). The range of $\mathrm{pH}$ chosen was based on the widely practiced $\mathrm{pH}$ of $4.8-5.0$ that is commonly recommended in conducting enzymatic saccharification of lignocelluloses (Wang et al., 2013). However, the results obtained in this study showed significant improvement in hemicellulose hydrolysis when enzymatic hydrolysis was conducted at lower $\mathrm{pH}(\mathrm{pH}$ 4.0-4.4), as opposed to $\mathrm{pH} 4.8-5.0$ which have been exclusively used in many literatures.

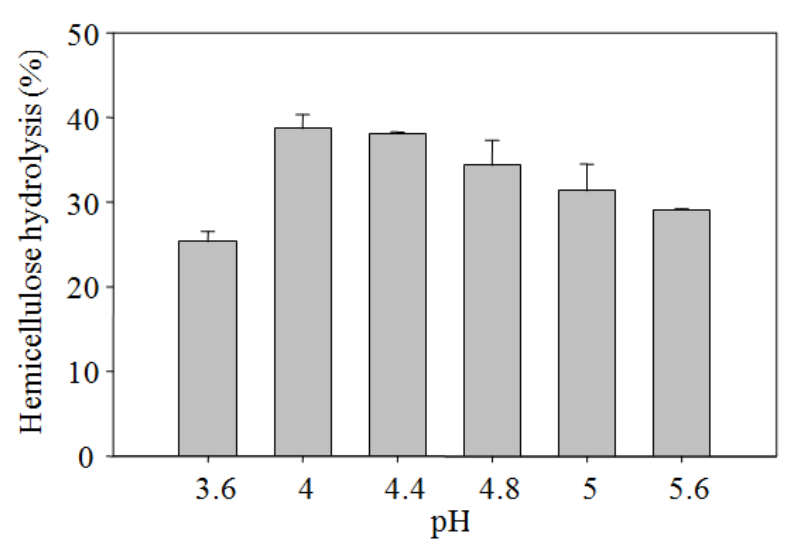

Fig. 3. Effect of different $\mathrm{pH}$ on hemicellulose hydrolysis of pre-treated kenaf. The hydrolysis was carried out using $3 \%$ of pre-treated kenaf with $400 \mathrm{U}$ of $\mathrm{Xyn} 2$ at $50^{\circ} \mathrm{C}$ in acetate buffer for $24 \mathrm{~h}$. Vertical bars represent standard deviations based on the average of at least three replicates and $\mathrm{p}$-value is $0.0073(\mathrm{p}<0.05)$

Hence, it was assumed that pre-treated kenaf hydrolysis at $\mathrm{pH} 4.0$ (more towards high acidic group) may have optimally altered the remaining lignin on the pre-treated kenaf surface compared to $\mathrm{pH} 4.4$ and above. Furthermore, different enzymes have different isoelectric points ( $\mathrm{pI}$ ); therefore, $\mathrm{pH}$ change could also affect electrostatic interactions between enzyme and substrate component (Lan et al., 2013). The $\mathrm{pH}$ can also affect substrate surface charges through surface functional groups by altering the surface's hydrophobicity. In this study, Xyn2 has a pI value of 9.0 and was very active hydrolysing the hemicellulosic kenaf at $\mathrm{pH}$ 4.0. When compared to the widely used $\mathrm{pH}$ of 5.0 , there was a significant 1.2 -fold $(21.4 \%)$ increase in sugar production from kenaf at $\mathrm{pH} 4.0$.

We also hypothesized that the ratio of the amount of xylanase bound productively to hemicellulose to the amount bound non-productively to lignin can vary with $\mathrm{pH}$. This was due to the $\mathrm{pH}$-induced lignin surface charge (via certain lignin functional groups) which could alter the surface hydrophilicity to reduce non-productive xylanase binding to lignin. Therefore, the $\mathrm{pH}$ range may slightly be different from the optimal $\mathrm{pH}$ range for a pure cellulosic or hemicellulosic substrate that does not contain lignin (Lan et al., 2013). This may also be one of the reasons why the $\mathrm{pH}$ of the present studied hemicellulosic kenaf hydrolysis differed from the commonly used $\mathrm{pH}$ as the pre-treated kenaf was not purely isolated. Furthermore, the degree of $\mathrm{pH}$-induced surface charges was different from lignin content, as well as for xylanase from different origins, due to the differences in the type and amount of surface functional groups they possessed. 
Table 3. The relationship between lignin content and $\mathrm{pH}$ optimum for hydrolysis

\begin{tabular}{llll}
\hline Substrate & Lignin content (\%) & $\mathrm{pH}$ used for hydrolysis & Reference \\
\hline Alkali-peracetic acid pre-treated kenaf & $5-10$ & 4 & This study \\
Green liquor pre-treated pulp & 26 & 4.8 & (Xue et al., 2012) \\
Woods & $16.6-37.9$ & $5.2-6.2$ & (Lan et al., 2013) \\
SPORL-pre-treated lodgepole pine solid + other woods & $20.2-34.7$ & 5.5 & (Wang et al., 2013) \\
Ultrasonic pre-treatment kenaf powder & $35-40$ & 5 & (Ninomiya et al., 2012) \\
Alkali and acid treated Switchgrass, corn stover & $19.74-26.7$ & 4.8 & (Zhang et al., 2012) \\
Alkali-peracetic acid pre-treated sugarcane bagasse & 18.45 & 4.8 & (Zhao et al., 2011) \\
Alkaline pre-treated perennial biomass & $9.81-11.8$ & 4.8 & (Sills and Gossett, 2011) \\
Ionic liquid pre-treated poplar and switchgrass & $19.5-23$ & 4.8 & (Samayam and Schall, 2010) \\
Alkaline pre-treated rice straw & 14.07 & 4.5 & (Cheng et al., 2010) \\
\hline
\end{tabular}

In Table 3, the relationship between lignin content and $\mathrm{pH}$ used for hydrolysis of several substrates was shown. It could be suggested that when a smaller amount of lignin content remains in the pre-treated substrate, a lower the $\mathrm{pH}$ is needed for optimum hydrolysis. This hypothesis was supported by a study on the hydrolysis of cassava starch factory residues using single commercial enzyme (Accelerase only) for the release of glucose. The study showed that with lower lignin content in the lignocellulose, the optimum $\mathrm{pH}$ required for the hydrolysis was also slightly reduced to lower $\mathrm{pH}$ values (Divya Nair et al., 2011). In a previous enzymatic study performed on kraft pulp (where the lignin content is normally $<10 \%$ ), the hydrolysis was performed at a much lower $\mathrm{pH}$ of 3.5 (Valchev et al., 1998). Table 3 demonstrated that the optimal $\mathrm{pH}$ range for enzymatic hydrolysis of complex and insoluble lignocellulosic substrates differs with the type of substrates.

\section{The Effect of Temperature on Hemicellulosic Kenaf Hydrolysis}

Hemicellulose hydrolysis of biomass is an endothermic reaction where it requires additional heat for the reaction to occur. Hence, the influence of temperature and the possible interactions between $\mathrm{pH}$ and temperature on the enzymatic hydrolysis was evaluated (Fig. 4). Both profiles for $\mathrm{pH} 4.0$ and $\mathrm{pH} 5.0$ showed a similar trend except at temperature $30^{\circ} \mathrm{C}$. At $30^{\circ} \mathrm{C}$, pH 5.0 exhibited higher hemicellulose hydrolysis compared to $\mathrm{pH}$ 4.0. Consequently, the increase of temperature was conducive to the hydrolysis (Jin et al., 2011). In this study, the hemicellulose hydrolysis of kenaf increased with the increase of the temperature but started to gradually decrease as the temperature exceeded $50^{\circ} \mathrm{C}$ for both $\mathrm{pH} 4$ and 5 . The highest hemicellulose hydrolysis of $38.67 \%$ was achieved at $\mathrm{pH} 4.0$ under $50^{\circ} \mathrm{C}$. This phenomenon could be explained by the ionization of water molecules. Enzymatic xylan hydrolysis in a buffer system appears to involve the ionization of two water molecules to dissociate into hydronium ions $\left(\mathrm{H}_{3} \mathrm{O}^{+}\right)$and hydroxyl ions $\left(\mathrm{OH}^{-}\right)$. Consequently, the increment in hemicellulose hydrolysis with temperature was due to the hydronium ions (in the buffer system) at high temperatures that collided with the $\beta-1,4$ linkages in the xylan structure, resulting in an efficient depolymerisation into XOS and xylose (Otieno and Ahring, 2012b). However, at $60^{\circ} \mathrm{C}$, there was a significant decrease in hemicellulose hydrolysis for both $\mathrm{pH} 4.0$ and 5.0 (Fig. 4).

The reduction in hemicelluloses hydrolysis most probably resulted from the denaturation of the enzyme at higher temperature which was above its optimum temperature that the protein could withstand. It has been previously investigated that temperature affect the rates of enzymatic reactions in two ways: (1) Higher temperatures increase the rate of the hydrolysis reaction but also; (2) increase the rate of thermal deactivation of the enzyme (Peterson et al., 1989). Thus, the thermal deactivation of enzymes counteracts the increase in reaction rates at higher temperatures and further leads to an exponential decay in enzymatic activity (Peterson et al., 1989). Therefore, the point where the enzyme started to deactivate is an important factor that needs to be considered in order to determine a suitable and optimum range of operating temperatures for an efficient hydrolysis. According to other studies, endo-xylanases have shown a wide range of optimum temperatures (40 to $75^{\circ} \mathrm{C}$ ) and $\mathrm{pH}(2.0-8.0)$ (Gonçalves et al., 2012). These huge variations of temperature and $\mathrm{pH}$ of a reaction are hypothesized to be strongly dependent on the type of enzyme (origin of xylanase) and substrate used. A control of enzyme-free reactions shows a very low hemicellulose hydrolysis with no significant changes with different temperatures. This proves that the enzymatic reaction with xylanase increases the hemicellulose hydrolysis significantly compared with the auto-hydrolysis.

\section{Effect of Hydrolysis Time on Hemicellulosic Kenaf Hydrolysis}

At fixed values of substrate concentration, enzyme loading, $\mathrm{pH}$ and temperature obtained from previous screening, it was observed that different enzymatic hydrolysis time significantly affected the percentage of hemicellulose hydrolysis, which ranged from 22.5 to $63.6 \%$, as shown in Fig. 5. The hydrolysis of hemicellulose in the first $6 \mathrm{~h}$ did not show a substantial increase in the reducing sugar yield $(<30 \%)$. 


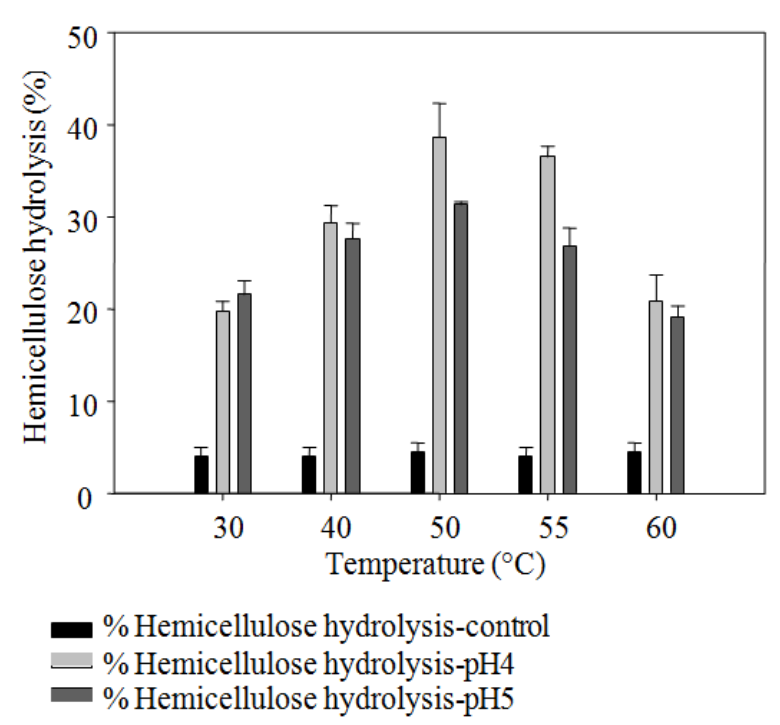

Fig. 4. Effect of different temperature on hemicellulose hydrolysis of pre-treated kenaf. The hydrolysis was carried out using $3 \%$ of pre-treated kenaf with $400 \mathrm{U}$ of Xyn2 in two different acetate buffers of $\mathrm{pH} 4.0$ and 5.0 for $24 \mathrm{~h}$. The control is enzyme-free reaction with the pre-treated kenaf under $\mathrm{pH}$ 4.0. Vertical bars represent standard deviations based on the average of at least three replicates. The $\mathrm{p}$-value is $0.0463(\mathrm{p}<0.05)$ for $\mathrm{pH} 4.0$ and 0.2763 for $\mathrm{pH}$ 5.0. The hemicellulose hydrolysis performed at $\mathrm{pH} 5.0$ is not significant $(\mathrm{p}>0.05)$

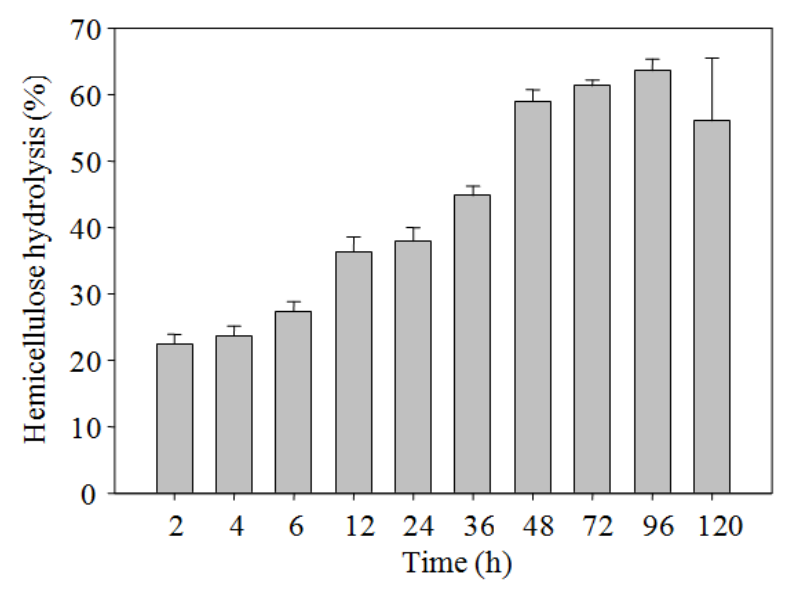

Fig. 5. Effect of different reaction time on hemicellulose hydrolysis of pre-treated kenaf. The hydrolysis was carried out using $3 \%$ of pre-treated kenaf with $400 \mathrm{U}$ of $\mathrm{Xyn} 2$ at $50^{\circ} \mathrm{C}$ in acetate buffer of $\mathrm{pH} 4.0$. Vertical bars represent standard deviations based on the average of at least three replicates and $p$-value is $0.0012(p<0.05)$

However, it started to gradually increase starting from 12 to $48 \mathrm{~h}$. Hence, at $12 \mathrm{~h}$ of incubation, it was believed that the xylanase have started to actively hydrolyze the hemicellulose backbone. However, the hemicellulose hydrolysis was slowed after some period and reached almost a stable stage (48-96 h), indicating that the level of easily accessible hydrolysis sites in the xylan chain have decreased, or this may have also been caused by the decreased in xylanase activity by the end product inhibition (Akpinar et al., 2009).

Another possible factor is based on the fact that the remaining available substrate becames less accessible for the enzyme attack due to fewer sites being exposed. This scenario could occur when there are still some branching groups left on the xylan backbone and, therefore, hindering further xylanase hydrolysis. From the time profile carried out on kenaf, $48 \mathrm{~h}$ was chosen as the best hydrolysis time. Although there was still an increase in hemicellulose hydrolysis at 72 and $96 \mathrm{~h}$, the increment was not significant $(<10 \%)$. Hence, a further addition in reaction time would not be economically feasible for an upscale process. Moreover, a reduction in the hemicellulose hydrolysis after $96 \mathrm{~h}$ might be due to a decrease in the concentration of accessible bonds available for hydrolysis, enzyme inhibition and enzyme deactivation (Ovissipour et al., 2009).

It was also been observed (during the experiment) that the reaction medium after $96 \mathrm{~h}$ turned out to be cloudy with thick slurry. This was probably one of the reasons for the drop in the hemicellulose hydrolysis as the mass transfer would not be as efficient as before. Furthermore, the error bar at $120 \mathrm{~h}$ (Fig. 5) showed a huge deviation. This further proved that the hemicellulose hydrolysis became ineffective and unstable with a longer reaction time. The highest degree of hydrolysis (DH \%) obtained from a similar enzymatic study performed on $4.4 \%(\mathrm{w} / \mathrm{v})$ wheat gluten was $65 \%$ after $48 \mathrm{~h}$ (Hardt et al., 2014). In comparison, the hemicellulose hydrolysis obtained from kenaf within the same period of reaction time (48 h) was $59.04 \%$ with only $3 \%(\mathrm{w} / \mathrm{v})$ substrate loading. This was a great improvement in terms of hydrolysis efficiency.

\section{The Effect of Enzyme Feeding Strategy on Hemicellulosic Kenaf Hydrolysis}

Different enzyme feeding strategy was also applied in this study to evaluate the effect towards hemicellulose hydrolysis of kenaf. Four different enzyme feeding strategies were tested with a total of $400 \mathrm{U}$ xylanase was added into the reaction system. For the first reaction, all of the $400 \mathrm{U}$ xylanase were initially added $(0 \mathrm{~h})$. Another $300 \mathrm{U}, 200 \mathrm{U}$ and $100 \mathrm{U}$ were added in the second, third and fourth reactions simultaneously (each reaction was performed in different flasks). After $24 \mathrm{~h}$, another 100 $\mathrm{U}, 200 \mathrm{U}$ and $300 \mathrm{U}$ were added in the second, third and fourth reactions (or flasks), respectively. All of the reactions were left for $120 \mathrm{~h} \mathrm{(5} \mathrm{days)} \mathrm{and} \mathrm{the}$ hemicellulose hydrolysis of kenaf was analyzed for every $24 \mathrm{~h}$. The results obtained are shown in Fig. 6 . The initial enzyme loading of $400 \mathrm{U}$ resulted in the highest hemicellulose hydrolysis at all sampling hour. 


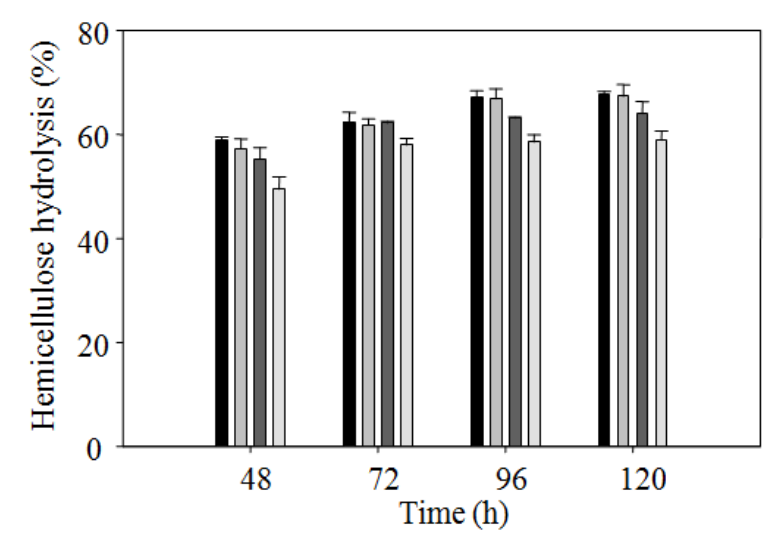

$$
\begin{aligned}
& \square 400 \mathrm{U}(0 \mathrm{~h}) \\
& \square 300 \mathrm{U}(0 \mathrm{~h})+100 \mathrm{U}(24 \mathrm{~h}) \\
& \square 200 \mathrm{U}(0 \mathrm{~h})+200 \mathrm{U}(24 \mathrm{~h}) \\
& \square 100 \mathrm{U}(0 \mathrm{~h})+300 \mathrm{U}(24 \mathrm{~h})
\end{aligned}
$$

Fig. 6. Effect of different enzyme feeding strategies on hemicellulose hydrolysis of pre-treated kenaf. The hydrolysis was carried out using $3 \%$ of pre-treated kenaf with $400 \mathrm{U}$ of $\mathrm{Xyn} 2$ at $50^{\circ} \mathrm{C}$ in acetate buffer of $\mathrm{pH} 4.0$ for $24 \mathrm{~h}$. Vertical bars represent standard deviations based on the average of at least three replicates. The pvalue is 0.0357 for the 1 st strategy $(\mathrm{p}<0.05), 0.0416$ for the 2nd strategy $(\mathrm{p}<0.05), 0.1068$ for the 3 rd strategy $(\mathrm{p}>0.05)$ and 0.1753 for the 4th strategy $(\mathrm{p}>0.05)$

The true reason behind the fact was hard to explain due to the complicated enzyme mechanism and substrate structure in the hydrolysis systems. It seemed that the amount of enzymes added at the initial stage played the most crucial role in determining the overall hydrolysis efficiency. It was hypothesized that the enzyme will effectively hydrolyze, degrade and alter the hemicellulose structure for the first $24 \mathrm{~h}$. Subsequently, it is believed that it will form a so-called biofilm layer around the kenaf surfaces. Hence, the second addition of enzyme after $24 \mathrm{~h}$ was hindered from effectively hydrolysing the hemicellulosic substrate. It has been previously explained that an enzyme fed-batch mode does not necessarily give higher yield than batch mode, but when the enzyme-adding method is suitable (such as the water-insoluble biomass concentration and the existence of any inhibitory compounds in the system), similar or slightly higher yields could be obtained (Hoyer et al., 2010). There may also be a potential increase in substrate recalcitrance or competition between the later added xylanase for reactive sites on the substrate with the available product in the medium over the hydrolysis time period (Chandra et al., 2011).

A comparison study was also conducted in this study to evaluate the hydrolysis performance between varieties of substrates (Table 4). The hydrolysis of the alkali-acid pre-treated kenaf resulted in a significantly high percentage of hemicellulose hydrolysis compared to the complex natural kenaf substrate.
Table 4. Comparison of xylanase $(400 \mathrm{U})$ hydrolysis on various substrates at $50^{\circ} \mathrm{C}(\mathrm{pH} 4.0)$ using $3 \%(\mathrm{w} / \mathrm{v})$ substrate loading after $48 \mathrm{~h}$ of incubation

\begin{tabular}{ll}
\hline Substrate & $\begin{array}{l}\text { Hemicellulose } \\
\text { hydrolysis (\%) }\end{array}$ \\
\hline Unpre-treated kenaf & $19.06 \pm 0.08$ \\
Alkali pre-treated kenaf & $32.44 \pm 0.12$ \\
Acid pre-treated kenaf & $21.38 \pm 0.11$ \\
Alkali-acid pre-treated kenaf & $59.04 \pm 0.07$ \\
\hline
\end{tabular}

${ }^{\mathrm{a} C o m m e r c i a l ~ s u b s t r a t e}$

This shows that the alteration of the kenaf structure (especially during the pre-treatment process) did improve the hemicellulose hydrolysis up to about 3-fold (Table 4). The un-pretreated kenaf resulted in a very poor hemicellulose hydrolysis $(19 \%)$ mainly due to the compact structure and restricted surface that prevent the enzyme from effectively hydrolyzing the targeted xylan composition in the hemicellulose. Furthermore, the use of one stage pre-treatment (alkali and acid pre-treatment, respectively) only resulted in a small increment in the hemicellulose hydrolysis. However, the complete hemicellulose hydrolysis from lignocellulosic biomass has never been achieved up to now due to the recalcitrant nature of plant biomass (Beukes and Pletschke, 2010). A full set of enzymes (branching and debranching) and a synergistic action between all the enzymes are required in order to achieve this goal.

Due to the fact of future potential of hemicellulose, several researches had been carried out aimed to improve the hemicellulose hydrolysis. An efficient biomass pre-treatment using thermal treatment in subcritical water (Öztürk et al., 2010) is one of the strategies applied for improving the hemicellulose hydrolysis as well as the benefits of no chemicals were used. Moreover, Carapito et al. (2009) had produced a high level of endo-1,4- $\beta$-xylanase, 1,4- $\beta$-xylosidase and bifunctional xylosidase/arabinofuranosidase in an engineered Escherichia coli. The enzymes displayed compatible $\mathrm{pH}$ and temperature-dependences, allowing their utilization for simultaneous substrate digestions (Carapito et al., 2009). Furthermore, a variety of multistep fractionation and purification procedures have been proposed to prepare hemicelluloses of desired purity from plant cell walls. These include using ethanol precipitation (Peng et al., 2010), ammonium sulfate precipitation (Subba Rao and Muralikrishna, 2006), iodine complex precipitation (Peng et al., 2012b), supercritical anti-solvent precipitation (Haimer et al., 2008) and many more. Clearly, some of the remaining challenges in this field include the design of efficient enzymatic systems for economic degradation of the plant cell wall, elucidation of the regulatory mechanisms and design of new enzyme functionalities via protein engineering (Shallom and Shoham, 2003). 


\section{Conclusion}

This study provides a clear explanation on the effect of several reaction conditions on the enzymatic hydrolysis of lignocellulose. The detail discussion therefore, underscores the importance of each substrate loading, enzyme loading, $\mathrm{pH}$, temperature and time towards obtaining an optimum hemicellulose hydrolysis on the pre-treated kenaf. The use of single xylanase on natural substrate further indicates that comprehensive knowledge of the reaction conditions will be indispensable for designing future optimized enzyme cocktails.

\section{Acknowledgement}

The authors gratefully thank University Teknologi Malaysia (Grant number 02G53) and the Ministry of Higher Education (Malaysia) for financial support and Everise Crimson (M) Sdn. Bhd. for providing us with the raw kenaf sample.

\section{Author's Contributions}

We certify that all persons listed as authors have made substantial contributions to the work reported in this manuscript.

Nur Izyan Wan Azelee: Carried out the data collecting, analysis and writing of the manuscript.

Jamaliah Md Jahim, Ahmad Fauzi Ismail, Siti Fatimah Zaharah Mohamad Fuzi, Roshanida A. Rahman and Nazlee Faisal Ghazali: Participated in giving advice and comments on the manuscript, especially on the discussion section.

Rosli Md Illias: Helped in coordination, drafting, editing of the manuscript and conducted the correspondence of the submitted paper.

\section{Ethics}

The authors declare no conflicts of interest and that this article conforms to the ethical standards specified by the American Journal of Agricultural and Biological Sciences.

\section{References}

Akpinar, O., K. Erdogan and S. Bostanci, 2009. Enzymatic production of xylooligosaccharide from selected agricultural wastes. Food Bioproducts Process., 87: 145-151.

DOI: $10.1016 /$ j.fbp.2008.09.002

Bailey, M.J., P. Biely and K. Poutanen, 1992. Interlaboratory testing of methods for assay of xylanase activity. J. Biotechnol., 23: 257-270.

DOI: 10.1016/0168-1656(92)90074-J
Beukes, N. and B.I. Pletschke, 2010. Effect of lime pretreatment on the synergistic hydrolysis of sugarcane bagasse by hemicellulases. Bioresource Technol., 101: 4472-4478.

DOI: $10.1016 /$ j.biortech.2010.01.081

Canilha, L., R.D.C.L.B. Rodrigues, F.A.F. Antunes, A.K. Chandel and T.S.D.S. Milessi et al., 2013. Bioconversion of hemicellulose from sugarcane biomass into sustainable products.

Carapito, R., C. Carapito, J.M. Jeltsch and V. Phalip, 2009. Efficient hydrolysis of hemicellulose by a Fusarium graminearum xylanase blend produced at high levels in Escherichia coli. Bioresource Technol., 100: 845-850.

DOI: 10.1016/j.biortech.2008.07.006

Carlos, M., G.J.D.M. Rocha, J.R.A. dos Santos, M.C.D.A. Wanderley and E.R. Gouveia, 2012. Enzyme loading dependence of cellulose hydrolysis of sugarcane bagasse. Quím. Nova, 35: 1927-1930. DOI: $10.1590 /$ S0100-40422012001000007

Carrillo, F., M. J. Lis, X. Colom, M. López-Mesas and J. Valldeperas. 2005. Effect of alkali pretreatment on cellulase hydrolysis of wheat straw: Kinetic study. Process Biochem., 40: 3360-3364.

DOI: $10.1016 /$ j.procbio.2005.03.003

Chandra, R.P., K. Au-Yeung, C. Chanis, A.A. Roos and W. Mabee et al., 2011. The influence of pretreatment and enzyme loading on the effectiveness of batch and fed-batch hydrolysis of corn stover. Biotechnol. Progress, 27: 77-85. DOI: 10.1002/btpr.508

Chen, Y., Y. Wen, J. Zhou, C. Xu and Q. Zhou, 2012. Effects of $\mathrm{pH}$ on the hydrolysis of lignocellulosic wastes and volatile fatty acids accumulation: The contribution of biotic and abiotic factors. Bioresource Technol., 110: 321-329. DOI: 10.1016/j.biortech.2012.01.049

Cheng, Y. and R.K. Prud'homme, 2000. Enzymatic degradation of guar and substituted guar galactomannans. Biomacromolecules, 1: 782-788. DOI: $10.1021 / \mathrm{bm} 005616 \mathrm{v}$

Cheng, Y.S., Y. Zheng, C. Yu, T. Dooley and B. Jenkins et al., 2010. Evaluation of high solids alkaline pretreatment of rice straw. Applied Biochem. Biotechnol., 162: 1768-1784. DOI: $10.1007 / \mathrm{s} 12010-010-8958-4$

Cara, C., M. Moya, I. Ballesteros, M.J. Negro and A. Gonzalez et al., 2007. Influence of solid loading on enzymatic hydrolysis of steam exploded or liquid hot water pretreated olive tree biomass. Process Biochem., 42: 1003-1009. DOI: $10.1016 /$ j.procbio.2007.03.012

Divya Nair, M.P., G. Padmaja and S.N. Moorthy, 2011. Biodegradation of cassava starch factory residue using a combination of cellulases, xylanases and hemicellulases. Biomass Bioenergy, 35: 1211-1218. DOI: $10.1016 /$ j.biombioe.2010.12.009 
Gonçalves, T.A., A.R.L. Damásio, F. Segato, T.M. Alvarez and J. Bragatto et al., 2012. Functional characterization and synergic action of fungal xylanase and arabinofuranosidase for production of xylooligosaccharides. Bioresource Technol., 119: 293-299. DOI: 10.1016/j.biortech.2012.05.062

Haimer, E., M. Wendland, A. Potthast, T. Rosenau and F. Liebner, 2008. Precipitation of hemicelluloses from DMSO/water mixtures using carbon dioxide as an antisolvent. J. Nanomater.

DOI: $10.1155 / 2008 / 826974$

Hames, B.R., S.R. Thomas, A.D. Sluiter, C.J. Roth and D.W. Templeton, 2003. Rapid biomass analysis: New tools for compositional analysis of corn stover feedstocks and process intermediates from ethanol production. Applied Biochem. Biotechnol., 105: 5-16. PMID: 12721471

Hardt, N.A., A.E.M. Janssen, R.M. Boom and A.J. van der Goot, 2014. Factors impeding enzymatic wheat gluten hydrolysis at high solid concentrations. Biotechnol. Bioeng., 111: 1304-1312. DOI: $10.1002 /$ bit.25197

He, J., B. Yu, K. Zhang, X. Ding and D. Chen, 2009. Expression of endo-1, 4-beta-xylanase from Trichoderma reesei in Pichia pastoris and functional characterization of the produced enzyme. BMC Biotechnol., 9: 1-10. DOI: 10.1186/1472-6750-9-56

Hodge, D., M.N. Karim, D. Schell and J. McMillan, 2009. Model-based fed-batch for high-solids enzymatic cellulose hydrolysis. Applied Biochem. Biotechnol., 152: 88-107.

DOI: $10.1007 / \mathrm{s} 12010-008-8217-0$

Hoyer, K., M. Galbe and G. Zacchi, 2010. Effects of enzyme feeding strategy on ethanol yield in fed-batch simultaneous saccharification and fermentation of spruce at high dry matter. Biotechnol. Biofuels, 3: 1-11. DOI: $10.1186 / 1754-6834-3-14$

Jin, Q., H. Zhang, L. Yan, L. Qu and H. Huang, 2011. Kinetic characterization for hemicellulose hydrolysis of corn stover in a dilute acid cycle spray flow-through reactor at moderate conditions. Biomass Bioenergy, 35: 4158-4164. DOI: 10.1016/j.biombioe.2011.06.050

Lan, T.Q., H. Lou and J.Y. Zhu, 2013. Enzymatic saccharification of lignocelluloses should be conducted at elevated pH 5.2-6.2. Bioenergy Res., 6: 476-485. DOI: 10.1007/s12155-012-9273-4

Lin, L., R. Yan, Y. Liu and W. Jiang, 2010. In-depth investigation of enzymatic hydrolysis of biomass wastes based on three major components: Cellulose, hemicellulose and lignin. Bioresource Technol., 101: 8217-8223. DOI: 10.1016/j.biortech.2010.05.084

Miller, G.L., 1959. Use of dinitrosalicylic acid reagent for determination of reducing sugar. Anal. Chem., 31: 426-428. DOI: 10.1021/ac60147a030
Modenbach, A.A. and S.E. Nokes, 2013. Enzymatic hydrolysis of biomass at high-solids loadings-A review. Biomass Bioenergy, 56: 526-544. DOI: $10.1016 /$ j.biombioe.2013.05.031

Mussatto, S., G. Dragone, M. Fernandes, A.F. Milagres and I. Roberto, 2008. The effect of agitation speed, enzyme loading and substrate concentration on enzymatic hydrolysis of cellulose from brewer's spent grain. Cellulose, 15: 711-721.

DOI: $10.1007 / \mathrm{s} 10570-008-9215-7$

Ninomiya, K., K. Kamide, K. Takahashi and N. Shimizu, 2012. Enhanced enzymatic saccharification of kenaf powder after ultrasonic pretreatment in ionic liquids at room temperature. Bioresource Technol., 103: 259-265. DOI: 10.1016/j.biortech.2011.10.019

Otieno, D.O. and B.K. Ahring, 2012a. The potential for oligosaccharide production from the hemicellulose fraction of biomasses through pretreatment processes: Xylooligosaccharides (XOS), Arabinooligosaccharides (AOS) and Mannooligosaccharides (MOS). Carbohydrate Res., 360: 84-92. DOI: 10.1016/j.carres.2012.07.017

Otieno, D.O. and B.K. Ahring, 2012b. A thermochemical pretreatment process to produce Xylooligosaccharides Arabinooligosaccharides (AOS) and Mannooligosaccharides (MOS) from lignocellulosic biomasses. Bioresource Technol., 112: 285-292.

DOI: 10.1016/j.biortech.2012.01.162

Ovissipour, M., A. Abedian, A. Motamedzadegan, B. Rasco and R. Safari et al., 2009. The effect of enzymatic hydrolysis time and temperature on the properties of protein hydrolysates from Persian sturgeon (Acipenser persicus) viscera. Food Chem., 115: 238-242.

DOI: $10.1016 /$ j.foodchem.2008.12.013

Öztürk, İ., S. Irmak, A. Hesenov and O. Erbatur, 2010. Hydrolysis of kenaf (Hibiscus cannabinus L.) stems by catalytical thermal treatment in subcritical water. Biomass Bioenergy, 34: 1578-1585. DOI: 10.1016/j.biombioe.2010.06.005

Pallapolu, V.R., Y.Y. Lee, R.J. Garlock, V. Balan and B.E. Dale et al., 2011. Effects of enzyme loading and $\beta$-glucosidase supplementation on enzymatic hydrolysis of switchgrass processed by leading pretreatment technologies. Bioresource Technol., 102: 11115-11120. DOI: 10.1016/j.biortech.2011.03.085

Peng, F., J. Bian, J.L. Ren, P. Peng, F. Xu and R.C. Sun, 2012a. Fractionation and characterization of alkaliextracted hemicelluloses from peashrub. Biomass Bioenergy, 39: 20-30. DOI: $10.1016 /$ j.biombioe.2010.08.034

Peng, F., P. Peng, F. Xu and R.C. Sun, 2012b. Fractional purification and bioconversion of hemicelluloses. Biotechnol. Adv., 30: 879-903.

DOI: 10.1016/j.biotechadv.2012.01.018 
Peng, F., J.L. Ren, F. Xu, J. Bian and P. Peng et al., 2010. Fractional study of alkali-soluble hemicelluloses obtained by graded ethanol precipitation from sugar cane bagasse. J. Agric. Food Chem., 58: 1768-1776. DOI: $10.1021 /$ jf 9033255

Peterson, R.S., C.G. Hill and C.H. Amundson, 1989. Effects of temperature on the hydrolysis of lactose by immobilized $\beta$-galactosidase in a capillary bed reactor. Biotechnol. Bioeng., 34: 429-437. DOI: $10.1002 /$ bit.260340403

Qiu, Z., G.M. Aita and M.S. Walker, 2012. Effect of ionic liquid pretreatment on the chemical composition, structure and enzymatic hydrolysis of energy cane bagasse. Bioresource Technol., 117: 251-256. DOI: 10.1016/j.biortech.2012.04.070

Roberts, K., D. Lavenson, E. Tozzi, M. McCarthy and T. Jeoh, 2011. The effects of water interactions in cellulose suspensions on mass transfer and saccharification efficiency at high solids loadings. Cellulose, 18: 759-773.

DOI: $10.1007 / \mathrm{s} 10570-011-9509-\mathrm{z}$

Romsaiyud, A., W. Songkasiri, A. Nopharatana and P. Chaiprasert, 2009. Combination effect of $\mathrm{pH}$ and acetate on enzymatic cellulose hydrolysis. J. Environ. Sci., 21: 965-970. DOI: $10.1016 / \mathrm{S} 1001-0742(08) 62369-4$

Saba, N., M. Jawaid, K.R. Hakeem, M.T. Paridah and A. Khalina et al., 2015. Potential of bioenergy production from industrial kenaf (Hibiscus cannabinus L.) based on Malaysian perspective. Renewable Sustainable Energy Rev., 42: 446-459. DOI: 10.1016/j.rser.2014.10.029

Samanta, A.K., N. Jayapal, A.P. Kolte, S. Senani and M. Sridhar et al., 2012. Enzymatic production of xylooligosaccharides from alkali solubilized xylan of natural grass (Sehima nervosum). Bioresource Technol., 112: 199-205.

DOI: $10.1016 /$ j.biortech.2012.02.036

Samayam, I.P. and C.A. Schall, 2010. Saccharification of ionic liquid pretreated biomass with commercial enzyme mixtures. Bioresource Technol., 101: 3561-3566. DOI: 10.1016/j.biortech.2009.12.066

Shallom, D. and Y. Shoham, 2003. Microbial hemicellulases. Curr. Opin. Microbiol., 6: 219 228. DOI: 10.1016/S1369-5274(03)00056-0

Sharma, S.K., K.L. Kalra and G.S. Kocher, 2004. Fermentation of enzymatic hydrolysate of sunflower hulls for ethanol production and its scale-up. Biomass Bioenergy, 27: 399-402.

DOI: 10.1016/j.biombioe.2004.03.005

Sills, D.L. and J.M. Gossett, 2011. Assessment of commercial hemicellulases for saccharification of alkaline pretreated perennial biomass. Bioresource Technol., 102: 1389-1398.

DOI: $10.1016 /$ j.biortech.2010.09.035
Silva, J.R.F., K.C. Cantelli, M.B.A. Soares, M.V. Tres and D. Oliveira et al., 2015. Enzymatic hydrolysis of non-treated sugarcane bagasse using pressurized liquefied petroleum gas with and without ultrasound assistance. Renewable Energy, 83: 674-679. DOI: $10.1016 /$ j.renene.2015.04.065

Subba Rao, M.V. and G. Muralikrishna, 2006. Hemicelluloses of ragi (Finger Millet, Eleusine coracana, Indaf-15): Isolation and purification of an alkali-extractable arabinoxylan from native and malted hemicellulose B. J. Agric. Food Chem., 54: 2342-2349. DOI: $10.1021 / \mathrm{jf058144q}$

Sun, Y. and J. Cheng, 2002. Hydrolysis of lignocellulosic materials for ethanol production: A review. Bioresource Technol., 83: 1-11. DOI: 10.1016/S0960-8524(01)00212-7

Teixeira, L., J. Linden and H. Schroeder, 1999. Alkaline and peracetic acid pretreatments of biomass for ethanol production. Applied Biochem. Biotechnol., 77: 19-34. DOI: 10.1385/ABAB:77:1-3:19

Tippkötter, N., A.M. Duwe, S. Wiesen, T. Sieker and R. Ulber, 2014. Enzymatic hydrolysis of beech wood lignocellulose at high solid contents and its utilization as substrate for the production of biobutanol and dicarboxylic acids. Bioresource Technol., 167: 447-455.

DOI: 10.1016/j.biortech.2014.06.052

Uçkun Kiran, E., O. Akpinar and U. Bakir, 2013. Improvement of enzymatic xylooligosaccharides production by the co-utilization of xylans from different origins. Food Bioprod. Process., 91: 565-574. DOI: 10.1016/j.fbp.2012.12.002

Valchev, I., L. Yotova and E. Valcheva, 1998. Kinetics of xylanase treatment of hardwood pulp. Bioresource Technol., 65: 57-60. DOI: 10.1016/S0960-8524(98)00020-0

Valtcheva, E., S. Veleva, G. Radeva and I. Valtchev, 2003. Enzyme action of the laccase-mediator system in the pulp delignification process. React. Kinet. Catal. Lett., 78: 183-191. DOI: $10.1023 / \mathrm{A}: 1022538621950$

Wan Azelee, N.I., J.M. Jahim, A. Rabu, A.M. Abdul Murad and F.D. Abu Bakar et al., 2014. Efficient removal of lignin with the maintenance of hemicellulose from kenaf by two-stage pretreatment process. Carbohydr. Polym., 99: 447-453.

DOI: 10.1016/j.carbpol.2013.08.043

Wang, T.H. and S. Lu, 2013. Production of xylooligosaccharide from wheat bran by microwave assisted enzymatic hydrolysis. Food Chem., 138: 1531-1535. DOI: 10.1016/j.foodchem.2012.09.124

Wang, Z.J., T.Q. Lan and J.Y. Zhum, 2013. Lignosulfonate and elevated $\mathrm{pH}$ can enhance enzymatic saccharification of lignocelluloses. Biotechnol. Biofuels, 6: 1-11. DOI: 10.1186/1754-6834-6-9 
Xue, Y., H. Jameel, R. Phillips and H.M. Chang, 2012. Split addition of enzymes in enzymatic hydrolysis at high solids concentration to increase sugar concentration for bioethanol production. J. Indust. Eng. Chem., 18: 707-714.

DOI: $10.1016 /$ j.jiec.2011.11.132

Ying, T.Y., L.K. Teong, W.N.W. Abdullah and L.C. Peng, 2014. The effect of various pretreatment methods on oil palm Empty Fruit Bunch (EFB) and kenaf core fibers for sugar production. Proc. Environ. Sci., 20: 328-335.

DOI: 10.1016/j.proenv.2014.03.041

Zhang, L., Y. Liu, X. Niu, Y. Liu and W. Liao, 2012. Effects of acid and alkali treated lignocellulosic materials on cellulase/xylanase production by Trichoderma reesei Rut C-30 and corresponding enzymatic hydrolysis. Biomass Bioenergy, 37: 16-24. DOI: 10.1016/j.biombioe.2011.12.044
Zhao, X., Y. Song and D. Liu, 2011. Enzymatic hydrolysis and simultaneous saccharification and fermentation of alkali/peracetic acid-pretreated sugarcane bagasse for ethanol and 2,3-butanediol production. Enzyme Microbial Technol., 49: 413-419. DOI: $10.1016 / j$.enzmictec.2011.07.003

Zhao, X.B., L. Wang and D.H. Liu, 2008. Peracetic acid pretreatment of sugarcane bagasse for enzymatic hydrolysis: A continued work. J. Chem. Technol. Biotechnol., 83: 950-956. DOI: 10.1002/jctb.1889 